\title{
APORTES TEÓRICOS E METODOLÓGICOS PARA A HISTÓRIA DA CIÊNCIA COM BASE NO MATERIALISMO HISTÓRICO-DIALÉTICO
}

\author{
APORTES TEÓRICOS Y METODOLÓGICOS PARA LA HISTORIA DE LA CIENCIA \\ BASADA EN EL MATERIALISMO DIALÉTICO HISTÓRICO
}

\section{THEORETICAL AND METHODOLOGICAL CONTRIBUTIONS FOR SCIENCE HISTORY BASED ON HISTORIC-DIALETIC MATERIALISM}

DOI: http://dx.doi.org/10.9771/gmed.v11i3.33700

\author{
Andriel Rodrigo Colturato ${ }^{1}$ \\ Luciana Massi2
}

\begin{abstract}
Resumo: O referencial marxista tem sido pouco utilizado na História da Ciência, sendo frequentemente acusado, no decorrer da história, de ideológico, geral e economicista, enquanto surgem outras abordagens que priorizam a análise do sujeito em detrimento da realidade objetiva. O objetivo deste trabalho é sistematizar uma abordagem historiográfica com base no materialismo histórico-dialético, discutindo aspectos históricos, teóricos e metodológicos, com a finalidade de propor formas de elaboração da história. Defendemos que é possível superar os paradigmas tradicionais por meio de uma historiografia marxista que revele elementos fundamentais nas discussões da História da Ciência.
\end{abstract}

Palavras chave: História da ciência. Materialismo histórico-dialético. Marxismo

Resumen: La referencia marxista ha sido poco utilizada en la historia de la ciencia, siendo frecuentemente acusada a lo largo de la historia como ideológica, general y economista, mientras surgen otros enfoques que priorizan el análisis del tema sobre la realidad objetiva. El objetivo de este trabajo es sistematizar un enfoque historiográfico basado en el materialismo histórico-dialéctico, discutiendo aspectos históricos, teóricos y metodológicos, para proponer formas de elaborar la historia. Se argumenta que es posible superar los paradigmas tradicionales a través de una historiografía marxista que revela elementos fundamentales en las discusiones de la historia de la ciencia.

Palabras clave: Historia de la ciencia. Materialismo histórico-dialéctico. Marxismo

Abstract: The Marxist reference has been scarcely used in the history of science. Throughout history, it has being frequently accused as ideological, general and economist. Meanwhile, other approaches arise that prioritize the analysis of the subject over the objective reality. The aim of this paper is to systematize a historiographical approach based on historical-dialectical materialism, discussing historical, theoretical and methodological aspects, in order to propose ways of history elaboration. It is argued that it is possible to overcome traditional paradigms through a Marxist historiography that reveals fundamental elements in the discussions of the history of science.

Keywords: History of science. Historical-dialectical materialism. Marxism

\section{As tendências na historiografia da ciência e a historiografia marxista}

Diferentemente da história geral (política, econômica e social), tal como discutida por Hobsbawm (2013), o referencial marxista aparece pontualmente na tradição da História da Ciência, área caracterizada por uma multiplicidade de abordagens historiográficas. Segundo Young (1996), mais se escreveu de forma 
implícita ou explicitamente antimarxista do que se estabeleceu tentativas de elaborar a História da Ciência em termos marxistas. Tal abordagem foi frequentemente apontada por autores da nova historiografia como ideológica, geral e economicista. Entretanto, a exemplo do que defende Gavroglu (2007), a historiografia marxista é frequentemente destacada como um marco, por ter introduzido a História da Ciência externalista em alternativa à abordagem internalista que vinha sendo trabalhada. Neste artigo, pretendemos situar historicamente a problemática da História da Ciência externalista e marxista em meio às principais discussões historiográficas que vieram a ser estabelecidas, para, posteriormente, sistematizar e propor a adoção de um método para a análise da História da Ciência que visa superar as críticas feitas à História da Ciência marxista. Argumentamos que essa abordagem supera os paradigmas tradicionais da historiografia e mantém uma interlocução com as correntes atuais.

No início do século XX, a História da Ciência era fortemente influenciada pela filosofia positivista, que considerava a Ciência como objetiva, neutra e de desenvolvimento acumulativo e linear, na medida em que adotava os métodos das Ciências Naturais e compreendia que o progresso social se identificava com o desenvolvimento das Ciências (GAVROGLU, 2007). A História da Ciência elaborada até então era de cunho internalista, pois o enfoque se voltava para as evidências e os fatos de natureza científica estavam relacionados a algum assunto ou determinado problema (MARTINS, 2005). Nesse período, a historiografia da ciência também se tornava mais rigorosa do que nos períodos anteriores, na medida em que se opunha aos conceitos ingênuos e abandonava as grandes sínteses, voltando-se para estudos cada vez mais microscópicos (MARTINS, 2001). Com o advento das teorias da relatividade, da quântica, da genética e da robótica e com a ocorrência de inúmeros desastres ambientais e guerras, surgiram dúvidas sobre a questão do continuísmo, da neutralidade científica e dos métodos positivistas (ALFONSO-GOLDFARB, 2004), o que abriu caminho para as abordagens sociais ou externalistas, incluindo a marxista.

Os primeiros trabalhos sobre a História da Ciência a partir de um referencial marxista foram apresentados no segundo Congresso Internacional de História da Ciência de Londres, em 1931, pela comitiva soviética (YOUNG, 1996). As discussões gravitavam em torno da tese de que os envolvidos no estudo de teorias científicas abstratas eram influenciados pelo meio social e sujeitos a influências de natureza política e econômica, questionando a neutralidade da Ciência (ALFONSO-GOLDFARB, 2004). Dentre os vários autores presentes, Boris Hessen ${ }^{3}$ obteve grande destaque por apresentar as raízes econômicas do pensamento dos Principia de Newton (HESSEN, 1931). Para ele, a maior parte das teorias do século XVII foram determinadas pelas necessidades técnicas e econômicas da época. Segundo Martins (2001, p. 24), isso “[...] foi visto na época (e é visto atualmente) por quase todos os historiadores da ciência como apresentando uma caricatura da revolução científica (e, em particular, do trabalho de Newton) que não resiste a uma crítica acadêmica, sendo superficial e inaceitável". Posteriormente, John Desmond Bernal4, influenciado pela política soviética da investigação programada e da aplicação das conquistas científicas (GAVROGLU, 2007), escreveu as obras Social Function of Science (BERNAL, 1946) e Science in History (BERNAL, 1969), procurando relacionar a Ciência com os aspectos sociais e econômicos (YOUNG, 1996). A segunda obra, que buscava cobrir um período de mais de dois mil anos e todas as áreas científicas, tanto em termos da História da 
Ciência, quanto da História Política e Econômica, foi considerada simplista e tendenciosa (MARTINS, 2001), ou, segundo Porter (1996), um marxismo vulgar e doutrinário.

Alexandre Koyré se opôs à abordagem externalista, salientando, por exemplo, que as orientações práticas da sociedade e as capacidades dos artesãos não eram suficientes para explicar grandes rupturas científicas como as de Galileu, Bohr e Einstein (GAVROGLU, 2007). Para Koyré, a Ciência é essencialmente teoria à procura da verdade, com um fim em si, inato, autônomo: daí a denominação dessa abordagem de "História das ideias" proposta por Thomas S. Kuhn (GAVROGLU, 2007). Segundo Porter (1996), alguns autores dessa vertente "internalista" que foram influenciados por Koyré são Alfred Rupert Hall, Ierome Bernard Cohen, Marshall Clagett, Richard Westfall, Alistair Cameron Crombie, Charles Coulston Gillispie, entre outros. Como salienta Porter (1996), certos aspectos não podem ser explicados a partir de um olhar social da Ciência, por exemplo, no que se refere a questões sobre como e por que existem disciplinas como a Química, a Física e a Biologia, pois há algo específico e intrínseco a cada uma delas que deve ser analisado de maneira interna.

A tradição marxista para a elaboração da História da Ciência reapareceu apenas após 1960, dessa vez abandonando as grandes sínteses e o economicismo. Segundo Porter (1996), Robert Maxwell Young, com escritos polêmicos, argumentou que é um erro dizer que a Ciência cresce de forma progressiva e sem ideologia, a exemplo da Sociobiologia, contaminada pelo darwinismo social. A partir dessa abordagem, para Porter (1996), passou-se a enfatizar apenas os "abusos" e não os "usos" da Ciência. A historiografia marxista foi novamente criticada na década de 1980, sendo revista a interpretação econômica do desenvolvimento histórico, promovendo um retorno à história biográfica, à prosopografia, ao estudo da história política, administrativa, religiosa e constitucional (THUILLIER; TULARD, 1991).

Outras abordagens sociológicas, defendidas por Max Weber, Robert King Merton e Karl Mannhein, influenciadas de alguma maneira pelo marxismo, priorizaram o contexto de origem em detrimento do contexto de justificação (YOUNG, 1996). Thomas Kuhn, Bruno Latour, Steeve Woolgar e Michel Foucault, passaram também a se preocupar com as dinâmicas sociais dos cientistas, das instituições e das pesquisas, além das influências sociais, políticas e econômicas e culturais, levando ao questionamento da neutralidade, objetividade, racionalidade e progresso da Ciência, a partir de uma forte visão relativista, negando as abordagens anteriores (MARTINS, 2011). De acordo com Porter (1996), Foucault, por exemplo, pautado no estruturalismo, nega qualquer referência à objetividade e trata a Ciência como um discurso entre outros, considerando o homem como sujeito do discurso, sendo o conhecimento uma forma de poder. Segundo Kragh (2002), Thomas Kuhn também influenciou os historiadores da ciência com sua tese de que os paradigmas da Ciência são apenas diferentes uns dos outros, impulsionando novos estudos sobre magia, alquimia e etnografia (ALFONSO-GOLDFARB, 2004). Outra abordagem que ganhou destaque foi a história cultural, tendo como uma das vertentes a micro-história, que desloca o enfoque das ideias e dos cientistas para suas práticas em torno dos instrumentos, dos costumes, das técnicas e do discurso científico (MODY, 2015).

Como se pode observar, as abordagens oscilaram entre externalistas ou internalistas, perspectivas objetivistas ou subjetivistas, contexto de origem ou contexto de justificação. Houve, então, uma proliferação 
de métodos e perspectivas que culminaram em um ecletismo por parte dos historiadores (KRAGH, 2002) e em uma aproximação com abordagens interdisciplinares que os obrigaram a pôr em dúvidas conceitos e métodos até então utilizados (GAVROGLU, 2007). No decorrer da história, a historiografia da ciência priorizou certos aspectos e negou outros, por exemplo a determinação econômica, questionando-a como horizonte válido de análise. Apesar da defesa da superação da dicotomia internalismo e externalismo e da dimensão de cunho social e cultural da Ciência (MARTINS, 2001), entendemos que essas abordagens se restringem às análises microscópicas e parciais.

Gavroglu (2007) adverte que muitos dos esforços que buscam renovação das abordagens se contradizem, na medida em que propõem uma receita exclusiva para o modo de escrever a História da Ciência. Nesse sentido, defendemos que uma abordagem social, orientada ontológica e epistemologicamente pelo materialismo histórico-dialético, embora tenha sido abandonada historicamente, se mostra uma forma de análise válida para se apreender os fenômenos da História da Ciência. Dessa forma, devemos estabelecer uma análise crítica, considerando as mencionadas problemáticas da História da Ciência de cunho marxista e incorporando por superação aspectos da nova historiografia da ciência. Para construir esse argumento, neste artigo, inicialmente apresentamos como a historiografia marxista tem sido utilizada para, em seguida, desenvolvermos teoricamente uma forma de análise da História da Ciência a partir do materialismo histórico-dialético.

\section{Marxismo e História da Ciência}

Robert M. Young, em seu texto intitulado Marxism and History of Science (YOUNG, 1996) define, em linhas gerais e de forma clara, o fulcro da abordagem marxista para a História da Ciência:

A característica que define a abordagem marxista na história da ciência é que a história das ideias científicas, das prioridades de pesquisa, dos conceitos da natureza e dos parâmetros de descobertas está enraizada em forças históricas que são, em última instância, econômicas (YOUNG, 1996, p. 77, tradução nossa).

Young (1996) demonstra três variações na abordagem marxista, mais ou menos atreladas à característica citada. A primeira trata da tendência da interpretação marxista da história pautada única e exclusivamente no prefácio de A Contribuição para a Crítica à Economia Politica, de Marx (2008), texto que sintetiza algumas das principais conclusões de Marx sobre os estudos da sociedade burguesa. Nesse texto, Marx (2008) estabelece que a totalidade das relações de produção constitui uma estrutura econômica, base para uma superestrutura política, jurídica e intelectual, voltada para as ideias. Desse modo, os historiadores consideravam as Ciências Naturais como parte de uma ideologia também movida única e exclusivamente pelas forças econômicas, embora Young (1996) aponte que uma leitura atenta invalide esse argumento. Essa leitura é denominada de "marxismo vulgar" ou "economismo".

A segunda tendência se baseia na teoria da mediação. Segundo essa leitura, a base econômica é a principal, mas não a única determinante do trabalho científico, tendo como influência as interações entre os vários elementos da superestrutura, como as formas políticas de lutas de classes, teorias políticas, jurídicas, filosóficas, visões religiosas e sistemas de dogmas (YOUNG, 1996). A centralidade da abordagem é 
conferida à categoria trabalho e a história é a chave para a compreensão da realidade. Os fenômenos sociais são apreendidos a partir das mediações das forças sociais e econômicas que envolvem a produção e reprodução da vida real (YOUNG, 1996), se distanciando, pois, da determinação da superestrutura pela estrutura e também do economismo. Há, deste modo, vários graus de relativa autonomia da Ciência, elasticidade e espaço para contradições, uma vez que esta não é determinada apenas pela estrutura (YOUNG, 1996). Em outras palavras, deve-se obter as mediações das forças sociais e econômicas envolvidas na produção e reprodução da vida real para uma leitura da totalidade da História da Ciência.

A terceira tendência na historiografia marxista apresentada por Young (1996) parte do ponto de vista da totalidade, que entende que a Ciência não é isolada da sociedade e cada aspecto da realidade é interconectado de modo recíproco. O estudo envolvendo as partes e o todo da realidade, no entanto, fez perder um dos aspectos determinantes que é o da superestrutura econômica.

Entendemos que a primeira tendência não parte de uma leitura atenta da obra marxista, devendo, portanto, ser superada por uma síntese das duas outras tendências. Desenvolveremos essa síntese com base em autores que sistematizaram o método em Marx, tais como Paulo Netto (2010, 2011) e Tonet (2013).

O trabalho é núcleo fundamental para uma teoria cuja lógica parte do ser social, a ontologia do ser social. Os fundamentos ontológicos, portanto, têm preponderância sobre os aspectos epistemológicos e a objetividade (conhecimento do ser, da realidade social) prevalece sobre a subjetividade (o conhecimento do sujeito), na medida em que o conhecimento é apenas uma das dimensões da totalidade, que é o ser social (TONET, 2013). O conhecimento e os procedimentos para sua apreensão partem do objeto, não do sujeito, não havendo, portanto, um conjunto de procedimentos estabelecidos previamente para se apreender o real. Ontologicamente, a concepção materialista da história carrega alguns aspectos fundamentais, segundo Paulo Netto (2010): a categoria de práxis constituída pelo trabalho, que se refere ao homem como ser prático e social, é ancorada nas categorias nucleares denominadas totalidade, contradição e mediação; os processos históricos são contraditórios, marcados pela tensão de interesses sociais; os processos históricos são marcados por sujeitos reais que se organizam como grupos sociais com interesses comuns; os projetos são constituídos por sujeitos determinados a partir de imperativos e possibilidades que se colocam concretamente no espaços e no tempos precisos; os sujeitos são conscientes, não atuam cegamente, mas sim direcionados pelo maior ou menor grau de conhecimento que têm dos limites e possibilidades da sua ação; os processos são conduzidos e tensionados por sujeitos que têm suas próprias finalidades e intenções. Esses fundamentos são mobilizados na análise da história. Explicitamos, a seguir, algumas considerações sobre essas categorias.

Lukács (2013) aponta que compreender a totalidade não é compreender tudo, mas sim a lógica determinante e determinada das partes articuladas com o todo, em sua processualidade. O todo, por sua vez, é o polo regente dos fenômenos, a totalidade histórico-social, permeado por contradições e mediações (TONET, 2013). Segundo Paulo Netto (2011), a questão crucial é apreender as relações entre processos de uma totalidade inclusiva (sociedade burguesa), que são mediadas pelos distintos níveis de complexidade e pela estrutura peculiar de cada totalidade. É exatamente tal estrutura peculiar que entendemos como uma unidade mínima de análise, uma unidade da totalidade, determinada também pelos fins da pesquisa, supondo, 
segundo Tonet (2013, p. 104), uma “[...] processualidade em que conhecimento e execução prática se vão determinando reciprocamente".

A partir do entendimento dessas categorias, é fundamental estabelecer o momento crítico da análise histórica marxista que, para Paulo Netto (2010), consiste na análise da particularidade como um campo de mediações entre universalidade (sociedade, global) e singularidade (indivíduo, local). Conforme aponta Lukács (1978, p. 88):

[...] é rico e variado o modo pelo qual a dialética de universal e particular se manifesta na realidade histórico-social e como seria falso deduzir antecipadamente destes processos, tão diversos um do outro, um esquema qualquer. A ciência autêntica extrai da própria realidade as condições estruturais e as suas transformações históricas, e se formula leis, estas abraçam a universalidade do processo, mas de um modo tal que deste conjunto de leis pode-se sempre retornar - ainda que frequentemente através de muitas mediações aos fatos singulares da vida. É precisamente esta a dialética concretamente realizada de universal, particular e singular.

Nenhum fenômeno se expressa somente em termos da singularidade ou da universalidade, mas esses opostos se identificam em contínua tensão dialética, contraditória e passível de ser apreendida por meio da compreensão das mediações que regem o fenômeno em particular. Mediações se referem aos aspectos da realidade e suas determinações histórico-sociais, que não são diretas, mas sim mediadas. "Essas mediações são necessárias porque não há uma relação direta e imediata entre o fim pretendido e a realidade objetiva" (TONET, 2013, p. 104). Nesse sentido, as contradições são aspectos inerentes à história que dizem respeito à própria lógica da realidade a partir de um ponto de vista dialético e materialista, enquanto as mediações são um conjunto de relações presentes nas contradições entre parte e todo e entre o que é singular e o que é universal.

\section{A identificação das mediações na História da Ciência}

Como afirma Paulo Netto (2010), com base na concepção de teoria da história em Marx, não é possível expressar o método sem sua relação com a própria história. Devemos lembrar ainda que "[...] não é o sujeito que organiza o objeto, mas, ao contrário, o objeto que organiza o sujeito" (TONET, 2013, p. 106). Dessa maneira, as formas de expressão das categorias ontológicas só se tornam coerentes junto ao objeto de análise, no caso, a História da Ciência, que é construída a partir dos diversos tipos de fontes historiográficas.

Na pesquisa em História da Ciência, devemos partir do empírico ou real aparente (o conteúdo das fontes historiográficas), proceder à análise (obtenção das mediações abstratas) e retornar ao concreto (a sistematização das determinações que regem o objeto). A análise das fontes historiográficas é o ponto de partida para as análises do historiador, cujos cuidados para manipulação, sistematizados pela nova historiografia da ciência, são destacados por Kragh (2002) e Martins (2005).

Algumas dessas fontes são obras de história geral e de historiadores da ciência (CONNER, 2005; HOBSBAWM; 1977; BERNAL, 1969; FARRINGTON, 1949), que de certo modo consideram a ontologia marxista para a análise histórica, abrangendo aspectos da totalidade histórico-social que estão presentes na 
dimensão universal. Ainda que pesquisadores de tendência marxista se aproximam apenas dessas fontes, defendemos que uma análise da História da Ciência, pautada no materialismo histórico dialético como método, só pode ser saturada de determinações na medida em que estabelecidas correlações com aspectos singulares da realidade, apesar de esse não ser o polo regente. Desse modo, a singularidade compõe a universalidade, assim como a universalidade compõe a singularidade. Segundo Tonet (2013, p. 113):

Isto indica que o caminho que nos leva do desconhecido ao conhecido não é absolutamente desprovido de qualquer indicação. Ele é balizado por elementos genéricos (abstratos, gerais) que vão se tornando menos genéricos (abstratos) na medida em que se aproximam do objeto específico. Assim, se soubermos que algo está articulado com todos os outros elementos, isto é, que faz parte de uma totalidade maior, e, portanto, não é uma partícula sem conexão alguma, isto nos permitirá buscar quais são essas conexões e quais os outros elementos com os quais está conectado. Deste modo, aqueles elementos genéricos servirão, de algum modo, de orientação quanto ao caminho a ser seguido.

Entendemos que algumas fontes, que se aproximam mais de aspectos singulares, são fontes primárias (elaboradas no contexto ou na época do objeto de estudo) ou secundárias (produções analíticas de historiadores sobre os objetos). As fontes podem variar desde livros específicos de história das ciências (SMITH, 1979; PARTINGTON, 1961; GILLISPIE, 1981; DEBUS, 2002; FILGUEIRAS, 1995, 2002), produções de cientistas (SEABRA, 1788, NEWTON, 1952; LAVOISIER, 2007; GILLISPIE, 1957), farmacopeias (PINTO, 1836), artigos de periódicos como os da Isis, ${ }^{5}$ publicada pela History of Science Society, Ambix ${ }^{6}$, Annals of Science ${ }^{7}$, Revista Brasileira de História da Ciência ${ }^{8}$ e bases de dados como IsisCBExplore ${ }^{9} \mathrm{e}$ Lusodat ${ }^{10}$ e Internet Arcbive ${ }^{11}$. Essas fontes podem variar entre as específicas de algum objeto (estudos de casos ou história vertical) e as gerais (histórias de longos períodos ou história horizontal) (KRAGH, 2002). Elas são a base para se apreender os elementos singulares e universais e estabelecer análises de forma sincrônica, que leva em conta o contexto da época, e diacrônica, que leva em conta o processo dos fatos em um contexto mais longo.

A análise inicial pode ser feita ainda com base na lógica formal, consistindo em um momento sincrético de organização, identificação, catalogação e classificação das informações. As técnicas de manipulação, análise e interpretação dos documentos darão origem a um conteúdo que deve ser confrontado com os determinantes histórico-sociais. Para isso, adotamos os sistemas analíticos e conceituais do método marxista: a identificação da unidade de análise e sua relação com o singular e com o universal para constituir as mediações particulares do fenômeno histórico, obtendo assim a síntese dos fenômenos históricos. Ressaltamos que Marx (2015) ainda diferencia o método da análise do método de exposição: uma vez encontrada a unidade mínima de análise e apreendidas as mediações particulares entre o singular e o universal do objeto, deve-se fazer o retorno para o real, estabelecendo a reconstrução sintética do objeto a partir da apreensão concreta do pensamento (PAULO NETTO, 2011).

Junto à forma crítica de análise exposta aqui, defendemos a superação por incorporação a partir da análise dos dados com base na nova historiografia da ciência. Alguns cuidados que devem ser tomados pelo pesquisador, como expõem Kragh (2002) e Martins (2005), dizem respeito ao anacronismo, à visão whig (ingênua), ao esquematismo, à ingenuidade de análise, à exaltação ou crítica a cientistas, à descrição de fatos e datas sem análises concretas, ao uso exclusivo de fontes secundárias (apudismo). Devemos evitar, 
ainda, que o estudo contemple apenas os "vencedores" e considere também os "derrotados", buscando analisar suas ideias e seu contexto. Esses recursos são claramente importantes, embora não suficientes para captar a História da Ciência em sua totalidade, movimento e contradição.

\section{Rumo a uma historiografia crítica da ciência}

A partir da abordagem historiográfica que foi exposta sucintamente, fizemos um esforço de superação dos paradigmas tradicionais da historiografia, mantendo interlocução com as correntes atuais, no que se refere aos cuidados com as fontes e ao modo de análise da história, buscando evitar o relativismo e o irracionalismo. Os aspectos metodológicos apontados são coerentes com os aspectos destacados por Saviani (2007) na elaboração de sua obra História da Ideias Pedagógicas do Brasil: o movimento de síncrese à síntese, por meio de categorias concretas (e não gerais e abstratas) como ferramentas conceituais utilizados para se apreender o real; o olhar analítico-sintético no trato das fontes, articulando-as sincrônica e diacronicamente a partir dos devidos cuidados historiográficos; a articulação do singular e do universal.

Saviani (2007) cita dois outros aspectos que devem ser levados em consideração, a título de reflexão: a perspectiva de longa duração e a atualidade da pesquisa histórica. Acreditamos que a proposta ilustrada, embora seja útil para a elaboração de estudos de casos históricos, como tem sido feito atualmente pela História da Ciência, só se concretiza à medida que se estabelece a análise de períodos longos, como defende Gramsci (1999), uma vez que permite identificar os movimentos orgânicos (estruturais) e os distinguir dos conjunturais, além de demonstrar os momentos de continuidade e ruptura dos fenômenos referentes à atividade científica. Com relação à atualidade da pesquisa histórica, não desejamos recuperar discussões e tendências tais como o pragmatismo - que defende a História da Ciência a favor de necessidades práticas, sustentada por Dewey - e o presentismo - tendência cética, idealista e subjetivista que afirma que a história do passado não tem finalidade em si própria, devendo ser guiada pelos problemas do presente (KRAGH, 2002) -, mas, sim, defender que a história não é desinteressada e que o presente se enraíza no passado e se projeta no futuro (SAVIANI, 2007). Desse modo se nega a neutralidade científica, mas não a objetividade, uma vez que a realidade em si (o mundo, a totalidade) existe independentemente do sujeito, podendo ser conhecida quando o objeto é saturado de determinações. Concordamos com Tonet (2013, p. 105) ao defender que: Ao superar a dicotomia entre subjetividade e objetividade, demonstrando que a própria
realidade é o resultado da síntese entre consciência (momento subjetivo) e realidade
(momento objetivo), síntese essa realizada pela prática social, Marx pode sustentar, de
modo sólido, a possibilidade de conhecer não apenas a aparência (o fenômeno), mas
também a essência (o númeno).

Ao conceber o pensamento de modo histórico, dialético e materialista, superamos as dicotomias entre sujeito e objeto, indivíduo e social, contexto de origem e contexto e justificação. Propomos, desse modo, que não se pretende elaborar a História da Ciência a partir de uma visão puramente sociológica, biográfica, das ideias, das descobertas, cultural ou das práticas científicas, mas, sim, demonstrar como desvelar a complexidade das relações e determinações próprias das Ciências ao longo da história. Desse 
modo, não se propõe a elaboração de grandes sínteses, ou a priorização da singularidade, como na microhistória. A Ciência é entendida como prática social humana, em que os atos singulares só fazem sentido no contexto social mais amplo, no universal. Por outro lado, o contexto universal só pode ser entendido a partir do ato teleológico dos cientistas (ou não cientistas) em sua singularidade. A História da Ciência consiste, portanto, na identificação das mediações particulares em uma dialética entre singular e universal. Uma das consequências dessa afirmação é o desaparecimento da dicotomia entre internalismo e externalismo. Como destacado por Young (1996), até mesmo a separação entre as histórias da ciência e da tecnologia, cujas áreas foram institucionalizadas de modo fragmentado, desaparece. Isso se deve ao fato de que o homem, ao compreender a causalidade da natureza para adaptá-la a si, cria novas necessidades que são sanadas pelo uso do aparato tecnológico de forma teleológica. Esse aspecto é evidenciado, por exemplo, na França na década de 1780, na qual a Química, ligada por tradição à prática de laboratório, era dedicada à solução de problemas produtivos em meio a uma sociedade de cultura científica (HOBSBAWM, 1969).

Pretendemos estabelecer aqui uma síntese de uma análise crítica da problemática do marxismo na História da Ciência, ao mesmo tempo que apresentamos várias fontes historiográficas, tanto para aqueles que se inserem no campo do marxismo, de modo geral, quanto para os da área da educação, tendo em vista o reconhecimento do potencial pedagógico da História da Ciência no ensino de Ciências. Tratando especificamente do campo da educação, consideramos que essa é uma contribuição para se iniciar um debate no campo da pedagogia-histórico-crítica, uma vez que, como estabelece Saviani (2011, p. 8), uma das tarefas a que se propõe essa pedagogia é a "Identificação das formas mais desenvolvidas em que se expressa o saber objetivo produzido historicamente, reconhecendo as condições de sua produção e compreendendo as suas principais manifestações, bem como as tendências atuais de transformação".

\section{Referências}

ALFONSO-GOLDFARB, A. M. O que é história da ciência. 1. ed. São Paulo: Brasiliense, 2004. (Série Primeiros Passos, 286).

BERNAL, J D. Ciência na história. Tradução de António Neves Pedro. Lisboa: Livros Horizonte, 1969. (Coleção Movimento).

BERNAL, J.D. The social function of science. London: George Routlegde \& SONS, 1946.

CONNER, C. D. A people's history of science. New York: Nation Books, 2005.

DEBUS, A. G. O homem e a natureza no Renascimento. Porto: Porto Editora, 2002.

FARRINGTON, B. Francis Bacon: Philosopher of Industrial Science. New York: Henry Schuman, 1949.

FILGUEIRAS, C. A. L. A revolução química de Lavoisier: uma verdadeira revolução?

Química Nova, São Paulo, v. 18, n. 2, 1995.

FILGUEIRAS, C. A. L. Lavoisier: o estabelecimento da Química Moderna. São Paulo: Odysseus, 2002.

GAVRoGLU, K. O passado das ciências como história. Tradução de Custódio Magueijo. Porto: Porto Editora, 2007. (Coleção História e Filosofia da Ciência).

GILLISPIE, C. C. (Org.). Dictionary of scientific Biography. New York: Charles Scribner's Sons, v. 2, 1981. 
GILLISPIE, C. C. The Natural History of Industry. Isis, v. 48, n. 4, p. 398-407, dez. 1957.

GOMES, G, F. A ciência guiada por fatores sociais: a abordagem de Boris Hessen e sua contribuição para a sociologia da ciência. In: HAYASHI, M.C.P.I.; RIGOLIN, C. C. D.; KERBAUY, M.T.M (orgs).

Sociologia da ciência: contribuições ao campo CTS. Campinas: Alínea, 2014. p. 41-58.

GRAMSCI, A. Cadernos do cárcere. Tradução de Carlos Nelson Coutinho. Rio de Janeiro: Civilização Brasileira, 1999.

HESSEN, B. As raízes sócio-econômicas dos principia de Newton. In: GAMA, R. (Org.) Ciência e Técnica: antologia dos textos históricos. São Paulo: T. A. Queiroz. 1992.

HESSEN, B. The social and economic roots of newton's 'principia.' In: International congress of the history of science and technology. 2. ed. Science at the Cross Roads: Papers Presented to the International Congress of the History of Science and Technology. London: Frank Cass. 1971.

HOBSBAWM, E. J. A era das revoluções. Rio de Janeiro: Paz e Terra, 1977.

HOBSBAWM, E. J. Sobre história. Tradução de Cid Knipel Moreira. São Paulo: Companhia das Letras, 2013.

LUKÁCS, G. O particular à luz do materialismo dialético. LUKÁCS, G. Introdução a uma estética marxista. Rio de Janeiro: Civilização Brasileira, 1978.

LUKÁCS, G. Para uma ontologia do ser social II. São Paulo: Boitempo, 2013.

MARTINS, L. A. P. História da ciência: objetos, Métodos e problemas. Ciência \& Educação. Bauru, v. 11, n. 2, p. 305-317, 2005.

MARTINS, R. A. Ciência versus historiografia: os diferentes níveis discursivos nas obras sobre história da ciência. In: ALFONSO-GOLDFARB, A. M.; BELTRAN, M. H. R. (orgs.). Escrevendo a História da Ciência: tendências, propostas e discussões historiográficas. São Paulo: EDUC / Livraria de Física / FAPESP, 2004. p. 115145.

MARTINS, R. A. História e história da ciência: encontros e desencontros. In: Actas do $1^{\circ}$. Congresso Luso-Brasileiro de História da Ciência e da Técnica (Universidade de Évora e Universidade de Aveiro), 2000. Évora: Centro de Estudos de História e Filosofia da Ciência da Universidade de Évora, 2001. p. 11-46.

LAVOISIER, A. L. Tratado Elementar de Química. São Paulo: Madras, 2007.

LÖWY, M. As aventuras de Karl Marx contra o Barão de Münchhausen: marxismo e positivismo na sociologia do conhecimento. Tradução de Juarez Guimarães, Suzanne Felice Léwy. São Paulo: Busca Vida, 1987.

MARX, K. Contribuição à crítica da economia política. 2. ed. Tradução de Florestam Florestan Fernandes. São Paulo: Expressão Popular, 2008.

MARX, K. Grundrisse: manuscritos econômicos de 1857-1858: esboços da crítica da economia política. Boitempo Editorial, 2015.

MODY, C. C. M. Scientific Practice and Science Education. Science Education, v. 99, n. 6, p. $1026-$ 1032, 2015.

NEWTON, Isaac. Mathematical Principles of Natural Philosophy: Optics. Tradução A. Motte. 2. ed. Chicago: Encyclopaedia Britannica, 1952. (Col. Great Books of Western World, v. 34).

PARTINGTON, J. R. A History of Chemistry. New York: St. Martin's Press, 1961, v. 4.

PAULO NETTO, J. Introdução ao estudo do método de Marx. São Paulo: Expressão popular, 2011.

PAULO NETTO, J. Relendo a teoria marxista da história. In: SAVIANI, D.; LOMBARDI, J.

C. História e história da educação: o debate teórico-metodológico atual. Autores Associados, 2018.

PAULO NETTO, J. Ainda vale a pena ler J. D. Bernal, o sábio. Blog da Boitempo, 2016. Disponível em: https://blogdaboitempo.com.br/2016/06/10/ainda-vale-a-pena-ler-j-d-bernal-o-sabio/. Acesso em: 25 set. 2019. 
PORTER, R. The history of science and the history of society. In: Olby, R. C. et al (orgs). Companion to the history of modern science. London: Routledge, 1996 Pp. 32-46.

SAVIANI, D. Pedagogia histórico-crítica: primeiras aproximações. 11. ed. Campinas: Autores Associados, 2011. 160 p.

SMITH, J. G. The Origins and early development of the heavy Chemical Industry in France. Oxford: Clarendon Press, 1979.

SAVIANI, D. História das ideias pedagógicas no Brasil. Campinas, SP: Autores Associados, 2007.

SEABRA, V. C. Elementos de chimica. Coimbra: [s.n.]. 1788.

THUILLIER, G.; TULARD, J. La méthode en histoire. Paris: Presses Universitaires de France, 1991.

TONET, I. Método científico: uma abordagem ontológica. São Paulo: Instituto Lukács, 2013.

YOUNG, R. M. Marxism and history of science. In: OLBY, R.C. et al. (eds.) Companion to the history of modern science. London: Routledge, 1996. p. 77-86.

\footnotetext{
Notas:

${ }^{1}$ Universidade Estadual Paulista (UNESP), Faculdade de Ciências, Bauru. Graduado em Licenciatura em Química pelo Instituto de Química de Araraquara (UNESP). Cursa mestrado acadêmico no Programa de Pós-graduação em Educação para a Ciência, da Faculdade de Ciências (UNESP) campus de Bauru. Orcid: http://orcid.org/0000-0002-4769-4308 Email: andrielcolturato@hotmail.com

2 Universidade Estadual Paulista (UNESP), Faculdade de Ciências e Letras, Araraquara. Doutora em Ensino de Química pelo Programa de Pós-Graduação Interunidades em Ensino de Ciências da Universidade de São Paulo. Professora assistente doutora do Departamento de Didática da Faculdade de Ciências e Letras de Araraquara e do Programa de Pós-Graduação em Educação para a Ciência da Faculdade de Ciências de Bauru da Universidade Estadual Paulista (UNESP). ORCID: http://orcid.org/00000001-8761-3181 Email: luciana.massi@unesp.br

3 Boris Hessen nasceu em Elisavetgrad (hoje Kirovohrad, na Ucrânia) e se formou em Física em 1928 pelo instituto dos professores vermelhos (GOMES, 2014). Tornou-se comunista e integrou o Conselho Militar Revolucionário entre 1919 e 1921, tendo trabalhado como professor do Departamento de Física da Universidade Estadual de Moscou (GOMES, 2014). Ocupou os cargos de membro da Academia de Ciências da Rússia, diretor do Instituto de Física de Moscou e membro da presidência do Conselho Científico Estadual, órgão responsável pela assessoria de planos sobre o desenvolvimento técnico-científico da União Soviética (GOMES, 2014). Hessen era um estudioso da mecânica relativística de Einstein e se mostrava independente ao pensamento imposto pelo stalinismo. A mecânica relativística não era aceita pelos soviéticos por perder o caráter materialista (newtoniano) sendo por esse motivo acusado de contrarrevolucionário (GOMES, 2014).

${ }^{4}$ John Desmond Bernal nasceu na Irlanda em 1901 e faleceu em Londres, em 1971. Fez carreira em Cambridge e em Londres (Birkbeck College), tendo sido membro da Hoyal Society. Foi apelidado de "sábio", por ser cientista de destaque nas áreas Física, Biologia, Cristalografia e História da Ciência, além de ser um grande adepto ao comunismo (PAULO NETTO, 2016). No entanto, Löwy (1987) qualifica sua obra The Social Function of Science como crítica aos valores da "ciência soviética", popular no regime stalinista, apesar de Bernal ter adotado esses valores em parte de sua vida. Paulo Netto (2016) considera que a mesma obra lançou as bases para a sociologia da ciência marxista.

5 A página de acesso ao conteúdo dessa revista está disponível em https://www.journals.uchicago.edu/toc/isis/current

${ }^{6}$ A página de acesso ao conteúdo dessa revista está disponível em https://www.tandfonline.com/loi/yamb20

7 A página de acesso ao conteúdo dessa revista está disponível em https://www.tandfonline.com/loi/tasc20

8 A página de acesso ao conteúdo dessa revista está disponível em https://www.sbhc.org.br/revistahistoria/public

9 A página de acesso à base de dados está disponível em http://isiscb.org/

10 A página de acesso à base de dados está disponível em http://www.ghtc.usp.br/lusodat.htm

11 A página de acesso à base de dados está disponível em https://archive.org/
} 